\title{
Performance evaluation of manual operated single row weeder for groundnut crop
}

\author{
RAM BHAVIN, M.S. KHARDIWAR, SHAILENDRA KUMAR AND B.P. SOLANKI
}

\begin{abstract}
An experiment was conducted to evaluate the field performance of developed manual operated weeder was carried out at Department of Farm Machinery and Power of College of Agricultural Engineering and Technology, Junagndh. Various parameters such as field capacity, weeding efficiency, draft requirement and performance index of the weeder were considered during the test. The developed weeder can work up to $4.0 \mathrm{~cm}$ depth of operation with field capacity of $0.0285 \mathrm{ha} / \mathrm{h}$. highest weeding efficiency was obtained (i.e. up to $80.42 \%$ ). draft requirement was $34.4 \mathrm{~kg}$ for $20 \mathrm{~cm}$ width of the weeder and the performance index of the developed weeder was obtained 1210.53 .
\end{abstract}

KEY WORDS : Weeder, Weeding efficiency, Field capacity, Field performance

How to cite this Article : Bhavin, Ram, Khardiwar, M.S., Kumar, Shailendra and Solanki, B.P. (2016). Performance evaluation of manual operated single row weeder for groundnut crop. Engg. \& Tech. in India, 7 (1) : 45-52. 